\title{
Thymosin beta 4 treatment improves left ventricular function after myocardial infarction and is related to Up-regulation of chitinase 3-like-1 in mice
}

\author{
Christoffer Stark ${ }^{1 *}$ (D) Mikko Helenius ${ }^{2}$, Pekka Taimen $^{3}$, Rasmus Kentala ${ }^{1}$, Antti Saraste ${ }^{4}$, Tero-Pekka Alastalo², \\ Timo Savunen ${ }^{1}$ and Juha Koskenvuo ${ }^{1}$
}

\begin{abstract}
Background: Thymosin beta 4 is a promising agent in preclinical regenerative and cardioprotection research. After myocardial injury it improves cell survival, reduces inflammation and activates epicardial progenitor cells. The peptide is also involved in cardiac purinergic signaling.

Methods: We investigated the peptide's therapeutic potential in a mouse model for myocardial infarction and performed microarray analysis in the early post-infarction period in order to identify new pathways for cardioprotection and also studied its influence on soluble purinergic enzyme activity. In this study 69 mice underwent ligation of the left anterior descending coronary artery. Thymosin beta 4 or vehicle was injected either intraperitoneally or intramyocardially and the mice were followed for 2, 5, 7 or 28 days. Echocardiography was performed 2 and 28 days after infarction. Biochemical analyses were performed to measure apoptosis, cardiomyocyte hypertrophy and inflammation.

Results: Treatment improved left ventricular function and reduced cardiac remodeling. The rate of apoptosis and amount of cardiac inflammatory cells were similar between groups. Microarray data showed a significant up-regulation of chitinase 3-like-1 and this was verified by quantitative RT-PCR. The activity of CD73 increased gradually during the first week after infarction and was significantly higher in treated animals compared to controls.

Conclusions: Thymosin beta 4 treatment had mild preventive effect on left ventricle remodeling after myocardial infarction. Treated animals showed higher levels of CD73 activity and chitinase 3-like-1, which are novel molecules possibly related to thymosin beta 4 mediated cardioprotection.
\end{abstract}

Keywords: Thymosin beta 4, Myocardial infarction, Cardioprotection, Echocardiography, Chitinase 3-like-1, CD73

\section{Background}

Thymosin beta 4 (TB4) is a naturally occurring G-actin sequestering peptide that has showed good cardioprotective potential in several animal studies. After myocardial infarction (MI) it reduces infarct size and remodeling of the left ventricle (LV) leading to improved cardiac function. It has also been shown to induce the migration of

\footnotetext{
* Correspondence: ckjsta@utu.fi

1 Research Centre of Applied and Preventive Cardiovascular Medicine,

University of Turku, Turku, Finland

Full list of author information is available at the end of the article
}

epicardial progenitors into to the damaged myocardium and is thought to aid in the repair of the heart after MI [1]. The cellular mechanisms responsible for these effects are partly mediated by phosphorylation of the survival kinase Akt (protein kinase B). The activation of the Akt pathway decreases cell necrosis and apoptosis as well as inflammation after ischemic insult in the heart [2]. Recently TB4 was linked to increased cell surface ATP production by acting through extracellular ATP synthase and it was speculated that the increase in local 
ATP production could influence cell behavior through purinergic signaling [3].

We wanted to test the effect of TB4 in a mouse MI model using standard biochemical methods for assessing cardioprotection and serial echocardiography to determine changes in left ventricular function and remodeling. Previous studies have mostly relied on comparing endpoint imaging results with baseline studies or sham groups [4-6]. Since infarct sizes with ligation models vary depending on technical success we wanted to determine the change in these parameters over time and compared early and late functional and structural outcome after MI, which better reflects disease progression. The influence of TB4 on myocardial mRNA expression early after infarction was investigated in order to identify new targets and signaling pathways for TB4. In addition we screened plasma samples for possible involvement of soluble purine-converting enzymes in TB4-mediated cardioprotection.

TB4 treatment reduced infarct expansion, left ventricular remodeling and improved cardiac function. The activity of the cardioprotective enzyme CD73 increased and chitinase 3-like-1 (Ch3l1), a novel acute phase protein was up-regulated in treated animals. This may be related to TB4 treatment or secondary to changes in the inflammatory response after MI.

\section{Methods}

\section{Animal experiments}

MI was induced in $8-10$ week-old male $\mathrm{FVB} / \mathrm{n}$ mice by permanent ligation of the left anterior descending artery (LAD) [7]. The animals were pre-anesthetized in an incubation chamber using 5\% isoflurane. Endotracheal intubation was performed using a $22 \mathrm{G}$ venous cannula and the animals were then connected to a ventilator (TOPO dual mode ventilator, Kent Scientific, Torrington, CT, USA). The respiratory rate was set to $100 / \mathrm{min}$ and anesthesia was maintained using $1.5 \%$ isoflurane with an oxygen flow of $2 \mathrm{l} / \mathrm{min}$. Hypothermia was prevented by keeping the mice on a heating pad. The anterior part of the thorax was shaved and the skin was disinfected. A longitudinal skin incision was made to the left of the sternum and the intercostalspace was opened using an electric cauterization pen. The ribs were retracted and the pericardium opened. For ligation an 8-0 prolene suture was tied around the middle portion of the LAD immediately below the left auricle. Total occlusion was confirmed by visualization of paleness in the apex of the heart. The ribs were approximated by a 5-0 figure-of-eight suture and the muscle and skin woundswere closed separately using 4-0 sutures. Anesthesia was interrupted and the animals kept on mechanical ventilation until spontaneous breathing occurred. The intubation tube was removed when motor activity returned. Post-operatively the animals received three
$1 \mathrm{mg} / \mathrm{kg}$ injections of buprenorphine (Temgesic, Schering-Plough, Espoo, Finland) every 8-10 h. The animals were housed in individual cages with a 12/ $12 \mathrm{~h}$ light-dark cycle and had ad libitum access to food pellets and water. Sacrifice was performed by cervical dislocation after $\mathrm{CO} 2$ asphyxiation. The thorax was opened and the heart dissected and weighed. The heart was cut into two equal sections along the long axis of the heart perpendicular to the septal wall. The anterior half was fixed in formalin and the posterior half of the heart was snap frozen in liquid nitrogen and stored at $-80{ }^{\circ} \mathrm{C}$.

\section{Study groups}

A total of 69 animals underwent ligation of the LAD and were divided into long-term and short-term study groups. For the long-term study, 45 animals were divided into three groups and followed for 4 weeks. The first group $(n=16)$ received daily intraperitoneal injections of TB4 (Genway Biotech, San Diego, CA, USA) (6 $\mathrm{mg} / \mathrm{kg}$ suspended in300 $\mu \mathrm{l}$ PBS) for 14 days. The first injection was given $1 \mathrm{~h}$ following the procedure. The second treatment group $(n=17)$ received three doses of TB4 (400 ng suspended in $10 \mu \mathrm{l}$ PBS) at 2, 7 and 14 days post-MI injected under echocardiographic control into the peri-infarct area of the anterior left ventricular wall. The control group $(n=12)$ received daily intraperitoneal injections of saline for 14 days post-MI.

The remaining 24 animals were included into the short-term study and divided into TB4 treatment groups $(n=5)$ and control groups $(n=3)$ and followed for 2,5 and 7 days after MI. TB4 $(6 \mathrm{mg} / \mathrm{kg}$ suspended in $300 \mu \mathrm{l}$ PBS) was administered intraperitoneally $1 \mathrm{~h}$ after the procedure and then daily. The control animals received equal volumes of plain PBS.

\section{Echocardiography}

In the 4 week study the animals underwent echocardiography at 2 and 28 days post-MI by an investigator blinded to group assignments. For imaging the animals were pre-anesthetized quickly with $5 \%$ isoflurane and placed on a heating pad. The animals were allowed to breathe spontaneously and anesthesia was maintained using $1.5 \%$ isoflurane administered through a nasal mask. Echocardiography was performed using a highfrequency small animal imaging platform (Vevo 2100, Fujifilm VisualSonics Inc, Toronto, Ontario, Canada). Parasternal longitudinal images at the level of the left ventricular outflow tract were used for measuring left ventricular dimensions and ejection fraction. Myocardial infarct size was determined by measuring the longitudinal length ratio of the akinetic myocardium with a wall thickness less than $50 \%$ of the normal compared to 
longitudinal extent of whole LV. Early and late measurements were compared for determining progression of LV remodeling and heart failure.

\section{Histology and immunohistochemistry}

Formalin fixed paraffin-embedded tissue samples were cut in $5 \mu \mathrm{m}$ thickness and stained with hematoxylin and eosin for histological evaluation. Infarct sizes were determined by measuring the length of the infarct area divided by the length of the entire free left ventricular wall in one slide. For cardiomyocyte hypertrophy measurement average myocardial cell diameters were calculated in 10 highpower (x40) visual fields of the preserved non-infarcted myocardium of the anterior left ventricular wall and of the peri-infarct area. Apoptotic cells in the infarct border zone were quantified using TUNEL (terminal uDTP nick-end labeling) assays as described previously [8]. In brief, paraffin-embedded sections were transferred to glassslides and treated with sodium-citrate solution and then digested with proteinase $\mathrm{K}$ in order to expose the DNA. DNA strand breaks were then labeled with digoxigeninddUTP and stained with alkaline phosphatase for visualization. TUNEL-positive cells were counted in 510 high-power visual fields $(x 40)$ per sample. Immunohistochemical staining was performed on paraffinembedded sections after antigen retrieval (microwaving in citrate buffer $\mathrm{pH}$ 6.0) according to the manufacturer's instructions. The primary antibodies were rabbit polyclonal anti-Ki-67 (1:3000, clone AB9260, Millipore), rabbit polyclonal anti-CD68 (1:100, cat. No. bs-0649R, Bioss antibodies) and rabbit polyclonal anti-chitinase 3like-1 (1:5000, cat. No. bs-1093R-A350, Bioss antibodies). The primary antibodies were detected with poly-HRP anti-rabbit IgG (1:1000, Bright Vision). All histological analyses were performed in a blinded manner.

\section{Microarray analysis and qRT-PCR}

Heart tissues samples from three treated and three control animals at 2 days post-MI were processed for microarray analysis. Tissues were lyced with Precellys ${ }^{\bullet} 24$ tissue homogenizer using $1.4 \mathrm{~mm}$ ceramic beads (CK14, Precellys). Total RNA was isolated using a Nucleospin RNA II kit (Macherey-Nagel, cat. No. 740955.250) according to the manufacturer's instructions. RNA quality was assessed using a Bioanalyzer (Agilent), prior to hybridization on IlluminaMouseWG-6 v2.0 Expression BeadChip at the Functional Genomics Unit Biomedicum (FuGU) core facility of the University Of Helsinki, Finland. Unpaired $t$-test was used to detect differentially expressed genes. Expression levels of Chitinase 3-like 1 was analyzed on samples from 3 animals in both groups 2 and 7 days after MI. Real time quantitative (qRT-PCR) mRNA expression levels were measured with SYBR Green real-time PCR using Reverse Transcriptase Core
Kit (Eurogentec, cat. No. RT-RTCK-05) for cDNA synthesis and SYBR Green Master Mix (Eurogentec, Mesa Green qPCR Master Mix Plus for SYBR assay, cat. no. RT-SY2X-06 + WOU) for PCR reaction. Samples were measured with a CFX96 Touch Real-Time PCR Detection System (Bio-Rad, CA, USA). Results were normalized against the expression levels of two housekeeping genes, $\beta$-actin and ribosomal S18, using CFX Manager ${ }^{\mathrm{ra}}$ software. Primer sequences for each gene were: CHI3L1(forw) 5'GCA CAC CTC TAC TGA AGC CA-3'(rev) 5'-GCT GGT GAA GTA GCA GAC CA-3': $A C T B$ (forw) 5'-GCA AGC AGG AGT ACG ATG AG-3' (rev) 5' TAA CAG TCC GCC TAG AAG CA-3': RSB18(forw) GAT GGG AAG TAC AGC CAG GT-3' (rev) TTT CTT CAG CCT CTC CAG GT-3'. All primers were from Oligomer (Oligomer Oy, Helsinki, Finland).

Plasma ATP, ADP and soluble purine-converting enzymes Plasma levels of circulating ATP, ADP and soluble purine-converting enzymes were measured from TB4 treated and control animals at 2, 5 and 7 days post-MI. For quantifying plasma ATP and ADP concentrations, plasma aliquots $(5 \mu \mathrm{l})$ were suspended in100 $\mu \mathrm{l}$ PBS, heat inactivated and essentially measured as previously described [9] using ATPlite assay kit (Perkin Elmer) according to the manufacturer's instructions. Samples were transferred into two parallel white 96-well plates along with (A) or without (B) $200 \mu \mathrm{M}$ UTP and $5 \mathrm{U} / \mathrm{ml}$ of NDP kinase from S. cerevisiae (Sigma). Sample set A gives luminescence signal from both ATP and ADP and set B only from ATP, which can be used to extract ADP concentration in plasma samples. Plasma hemoglobin concentrations, which did not exceed $4.0 \mathrm{mg} / \mathrm{dl}$ (data not shown) were determined with Drabkin's reagent (Sigma). For analysis of soluble, purine-converting enzyme activities plasma aliquots $(10 \mu \mathrm{l})$ were suspended to RPMI-1640 media in 96-well flat bottom clear plates. Enzymatic activities were determined at $37{ }^{\circ} \mathrm{C}$ in a final volume of $80 \mu \mathrm{l}$ containing $4 \mathrm{mM} \beta$-glycerophosphate. Specific reaction conditions were optimized for each enzyme separately: (1) for ATPase, plasma suspension was incubated for $40 \mathrm{~min}$ with $300 \mu \mathrm{M}$ [2,8-3H] ATP (American Radiolabelled Chemicals, St. Louis, MO) as appropriate substrate; (2) ADPase was assayed with $250 \mu \mathrm{M}[2,8-3 \mathrm{H}]$ ADP (Perkin Elmer, Boston, MA) and incubated for $50 \mathrm{~min}$ with $10 \mu \mathrm{M}$ P1,P5-Di(Adenosine-5') Pentaphosphate (Ap5A, Sigma) to inhibit backward adenylate kinase (AK) activity; (3) ecto-5'-nucleotidase (CD73) activity was determined after 40-min incubation with $250 \mu \mathrm{M}$ [2-3H] AMP (Amersham, UK); (2) AK and nucleoside diphosphate kinase (NDPK) were assayed with $450 \mu \mathrm{M}$ [3H] AMP for $30 \mathrm{~min}$ or with $1000 \mu \mathrm{M}$ [3H] ADP for $10 \mathrm{~min}$ as respective phosphorus acceptors in the presence of 800-2000 $\mu \mathrm{M} \gamma$-phosphate-donating ATP. After selected 
incubation times, reactions were stopped by applying sample aliquots of the mixture onto Alugram SIL G/ UV254 sheets (Macherey-Nagel, Duren, Germany). $3 \mathrm{H}$-labeled nucleotides and nucleosides were separated by thin-layer chromatography (TLC) using appropriate solvent mixture: 1-butanol, iso-amyl alcohol, diethylene glycol monoethylether, ammonia solution, and milli-Q-aqua (9:6:18:9:15) and then quantified by scintillation $\beta$-counting as previously [9].

\section{Statistical analysis}

Results are presented as means $\pm \mathrm{SD}$. Student's $t$-test was used for single comparative analysis and one-way ANOVA with Tukey's or Dunnett's tests for multiple comparisons. A $p$-value $<0.05$ was considered statistically significant in all analyses.

\section{Results}

\section{Survival and weight gain}

In the long-term study 16 out of 45 animals died: 6 in the intraperitoneal treatment group, 7 in the intramyocardial treatment group and 3 in the control group. The remaining 29 animals survived for the complete duration of the study. All operated animals in the short-term study completed the follow-up period. Most deaths were considered cardiogenic as the most common finding at autopsy was a ruptured left ventricular wall with hemorrhage into the pleural and pericardial cavities. Kaplan-Meier plots did not show statistically significant mortality rates between the groups $(p=0.69)$. At 28 days post-MI control animals had gained more weight than treated animals. Change in body weight was otherwise similar between the groups. Heart weight to body weight ratios were similar at all different time points in all groups (Table 1).

\section{TB4 treatment reduces post-infarction remodeling and improves LV function}

Echocardiography was performed 2 days and 4 weeks after infarction to determine left ventricular remodeling. One animal in the intramyocardial and 2 animals in the intraperitoneal TB4 treatment groups were excluded from functional analysis due to persistent ventricular tachycardia during imaging. When comparing ejection fraction (EF), end-systolic volume (ESV), end-diastolic volume (EDV) and MI sizes at the two time-points, no statistically significant differences were observed between the groups (Table 2). The absolute changes in these parameters over time were however significant in favor of TB4 treated animals (Fig. 1). While EF in the control group decreased by $10.1 \%$ during the follow-up period only a $2.0 \%$ decrease in the intraperitoneal and a $6.7 \%$ increase in the intramyocardial treatment groups were observed. Furthermore, infarct area expansion and increase in ESV and EDV during follow-up was more obvious in control animals than in either treatment group.

\section{Myocardial cell proliferation, hypertrophy, apoptosis and cardiac inflammation}

All samples showed very low numbers of cells positive for the proliferation marker Ki-67 with no differences between the control, intraperitoneal and intramyocardial groups at 4 weeks $(0.97 \pm 0.12 \%$ versus $1.37 \pm$ $0.38 \%, p=0.42$ and $1.4 \pm 0.58 \%, p=0.38)$. Cardiomyocyte sizes, reflecting hypertrophy, were similar at 4 weeks both in the infarct region $(27.1 \pm 2.2 \mu \mathrm{m}$ vs. $26.6 \pm 3.1 \mu \mathrm{m}, p=0.91$ and $24.4 \pm 3.4 \mu \mathrm{m}, p=0.09$ and in the non-infarcted left ventricle $(25.1 \pm 2.3 \mu \mathrm{m}$ vs. $24.6 \pm 2 \mu \mathrm{m}, p=0.89$ and $25.6 \pm 3 \mu \mathrm{m}, p=0.93$. In the short-term study, infarct sizes were similar in control and TB4 treated animals (Fig. 2a). The number of TUNEL-positive apoptotic myocardial cells did not differ at 2 days $(7.2 \pm 4.5$ versus $8.4 \pm 1.5$ cells/visual field, $p=0.75), 5$ days $(1.2 \pm 0.5$ vs. $1.1 \pm 0.3$ cells/visual field, $p=0.74)$ or 7 days $(0.7 \pm 0.5$ vs. $0.6 \pm 0.4$ cells/ visual field, $p=0.8$ ) post-MI (Fig. 2b). There was an increase in CD68 positive macrophages in both groups between day $2(3.6 \pm 1.4$ cells/field vs. $1.5 \pm 1.1$ cells/ field, $p=0.11)$, day $5(11.0 \pm 5.1$ cells/field vs. $14.6 \pm$ $9.5, p=0.60)$ and day $7(19.5 \pm 8.4$ cells/field vs. $24.8 \pm$ 14.9 cells/field, $p=0.62$ ) post-MI without significant differences between the groups (Fig. 2c). These results suggest that TB4 had no significant influence on programmed cell death or macrophage infiltration at the time points observed.

Table 1 Effect of thymosin beta 4 treatment on body and heart weight after myocardial infarction

\begin{tabular}{|c|c|c|c|c|c|c|c|c|c|}
\hline & \multicolumn{2}{|l|}{ Day 2} & \multicolumn{2}{|l|}{ Day 5} & \multicolumn{2}{|l|}{ Day 7} & \multicolumn{3}{|l|}{ Day 28} \\
\hline & $\begin{array}{l}\text { Control } \\
(n=3)\end{array}$ & $\begin{array}{l}\text { TB4i.p. } \\
(n=5)\end{array}$ & $\begin{array}{l}\text { Control } \\
(n=3)\end{array}$ & $\begin{array}{l}\text { TB4 i.p. } \\
(n=5)\end{array}$ & $\begin{array}{l}\text { Control } \\
(n=3)\end{array}$ & $\begin{array}{l}\text { TB4 i.p. } \\
(n=5)\end{array}$ & $\begin{array}{l}\text { Control } \\
(n=9)\end{array}$ & $\begin{array}{l}\text { TB4 i.p. } \\
(n=10)\end{array}$ & $\begin{array}{l}\text { TB4 i.mc. } \\
(n=10)\end{array}$ \\
\hline Body weight at day 0 (g) & $25.8 \pm 0.2$ & $25.4 \pm 1.9$ & $24.2 \pm 0.9$ & $24.6 \pm 2.3$ & $25.5 \pm 1.3$ & $25.5 \pm 0.9$ & $26.6 \pm 1.5$ & $27.9 \pm 2.3$ & $27.0 \pm 1.3$ \\
\hline$\Delta$ body weight day 0 vs day $28(\mathrm{~g})$ & $-1.9 \pm 2.3$ & $-1.9 \pm 1.1$ & $-0.5 \pm 0.9$ & $-0.8 \pm 0.7$ & $0.4 \pm 1.3$ & $-2.5 \pm 2.4$ & $3.2 \pm 1.0$ & $1.5 \pm 1.6^{*}$ & $2.1 \pm 1.6$ \\
\hline Heart weight (mg) & $114 \pm 2$ & $117 \pm 3$ & $118 \pm 13$ & $118 \pm 7$ & $134 \pm 16$ & $120 \pm 11$ & $152 \pm 16$ & $151 \pm 26$ & $148 \pm 20$ \\
\hline Heart to body weight ratio $(\mathrm{mg} / \mathrm{g})$ & $4.8 \pm 0.4$ & $5.0 \pm 0.2$ & $5.1 \pm 0.5$ & $5.0 \pm 0.4$ & $5.2 \pm 0.8$ & $5.2 \pm 0.3$ & $5.1 \pm 0.4$ & $4.9 \pm 0.5$ & $5.1 \pm 0.6$ \\
\hline
\end{tabular}

${ }^{*}=p<0.05$ compared to control, all other $p=$ NS (mean \pm SD) 
Table 2 Echocardiography data 2 and 28 days post-MI

\begin{tabular}{|c|c|c|c|}
\hline & $\begin{array}{l}\text { Control } \\
(n=9)\end{array}$ & $\begin{array}{l}\text { TB4 i.p. } \\
(n=8)\end{array}$ & $\begin{array}{l}\text { TB4 i.mc. } \\
(n=9)\end{array}$ \\
\hline EF at day 2 post-Ml (\%) & $42.5 \pm 4.0$ & $41.6 \pm 2.6$ & $39 \pm 3.8$ \\
\hline EF at day 28 post-MI (\%) & $38.2 \pm 6.3$ & $41.5 \pm 3.9$ & $41.2 \pm 4.5$ \\
\hline ESV at day 2 post-MI $(\mu \mathrm{l})$ & $43.3 \pm 7.5$ & $45.5 \pm 5.2$ & $48.7 \pm 9.6$ \\
\hline ESV at day 28 post-MI $(\mu l)$ & $58.5 \pm 18$ & $49 \pm 7.0$ & $51.7 \pm 14.3$ \\
\hline EDV at day 2 post-MI $(\mu \mathrm{l})$ & $75.2 \pm 10.3$ & $77.9 \pm 8.4$ & $79.3 \pm 11.9$ \\
\hline EDV at day 28 post-MI $(\mu \mathrm{l})$ & $93.3 \pm 21.3$ & $83.6 \pm 7.5$ & $86.9 \pm 17.7$ \\
\hline MI at day 2 post-Ml by echo (\%) & $13.4 \pm 5.7$ & $17.7 \pm 14.1$ & $21 \pm 8.9$ \\
\hline Ml at day 28 post-Ml by echo (\%) & $21.7 \pm 10$ & $18 \pm 10.5$ & $20.5 \pm 9.8$ \\
\hline
\end{tabular}

All $p=\mathrm{NS}($ mean $\pm \mathrm{SD})$

$E F$ left ventricle ejection fraction, ESV left ventricle end-systolic volume, EDV left ventricle end-diastolic volume, $M I$ myocardial infarction

\section{Epicardial gene expression and Chitinase 3-like-1}

To get further insight on the protective mechanisms of TB4, we carried out whole genome gene expression analysis on cardiac tissue samples. At 2 days post-MI there was significant up-regulation of four genes in TB4 treated animals compared to controls (Table 3.). Two of the genes, start domain containing 10 (Stard10) and chitinase 3-like-1 (ch3l1), have previously been characterized as epicardial signature genes [10]. CD209f and coiled-coil domain containing 80 (ccdc80) are in turn related to dendritic cell-mediated endocytosis and modulation of glucose and energy homeostatis, respectively. We also observed up-regulation of some other epicardial signature genes (uroplakin, dermokine, complement components 2 and 3) but these changes remained statistically insignificant. We validated the upregulation of Ch3l1 with qRT-PCR, which showed a 4-fold increase in mRNA expression at 2 days $(p=0.07)$ and a 2 fold increase at 7 days $(p<0.05)$ post-MI compared to controls (Fig. 3a). The amount of Ch3l1 positive cells was slightly higher in TB4 treated animals at 2 (17.8 \pm 3.9 cells/ field vs. $22.0 \pm 5.6$ cells/field, $p=0.34), 5(19.1 \pm 9.5$ cells/ field vs. $33.3 \pm 14.6, p=0.23)$ and 7 days $(21.9 \pm 11.5$ cells/ field vs. $26.7 \pm 10.1$ cells/field, $p=0.62$ ) after MI but the differences remained statistically insignificant (Fig. 3b).

\section{ATP/ADP levels and purinergic ecto-enzyme activity}

Plasma ATP and ADP levels were similar between the groups at all time points. There was a slight increase in ATP and ADP at 7 days post-MI in both groups but these differences were statistically insignificant compared to earlier time points (Fig. 4a and b). The activity of soluble ATP and ADP hydrolyzing enzymes remained unaltered at allthree time points (Fig. $4 \mathrm{c}$ and d). The activity of CD73, which converts AMP to adenosine increased significantly in TB4 treated animals over time and was significantly higher at 7 days post-MI compared to controls $(483 \pm 47$ vs. $643 \pm 76 \mu \mathrm{mol} / \mathrm{h} / \mathrm{ml}, p<0.05)$ (Fig. 4e). The enzymes AK and NDPK, which catalyze the production of ADP and ATP, showed similar and consistent levels of activity in all samples (Fig. 4f and g). Overall NDPK activity was clearly higher than for AK in both groups.
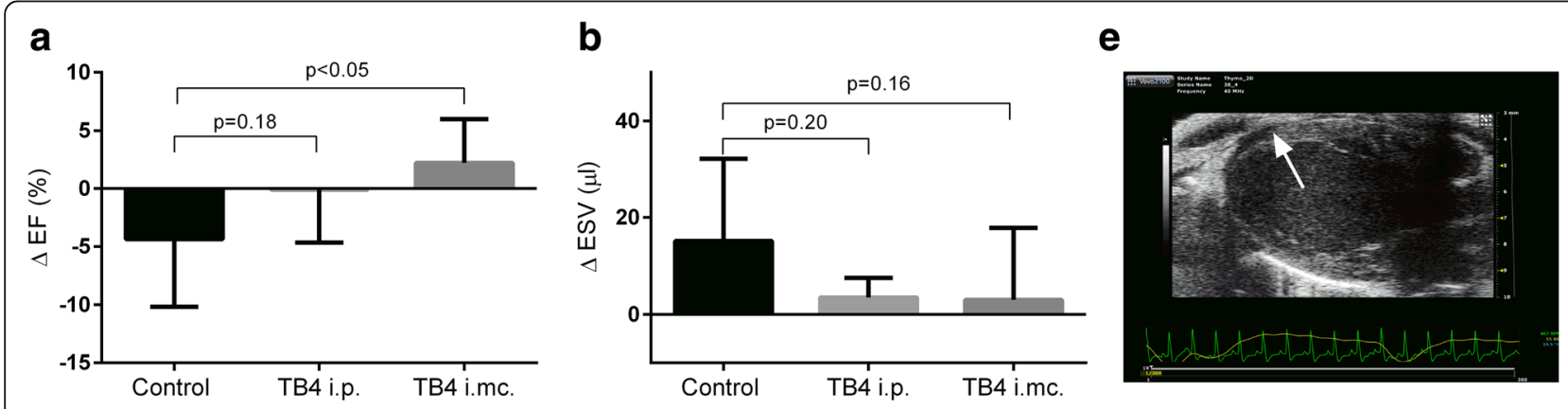

C

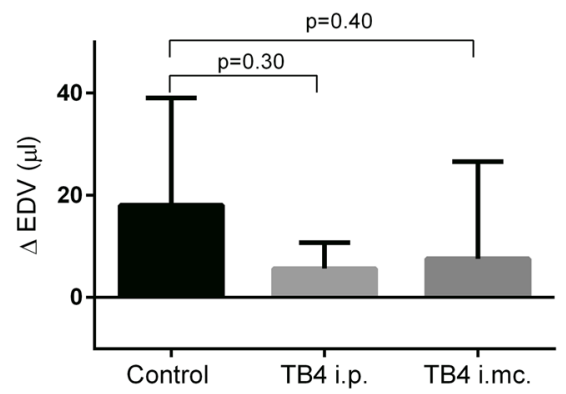

d

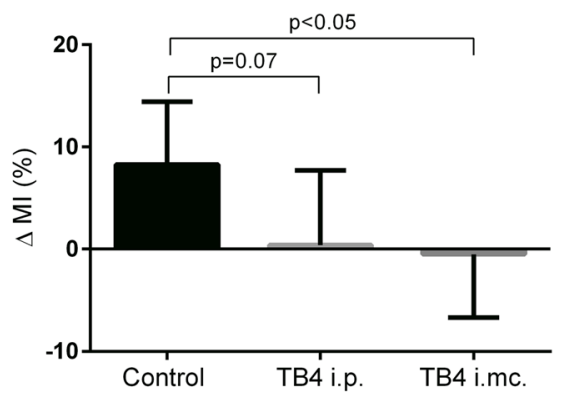

f

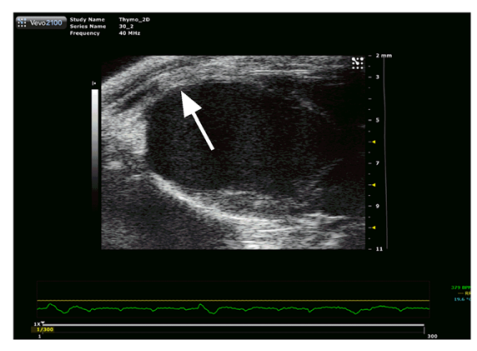

Fig. 1 Absolute change in EF (a), ESV (b), EDV (c) and MI size (d) between days 2 and 28 in controls and TB4 treated animals (i.p. and i.mc.). Representative images of early (e) and late (f) imaging in the same animal. Arrows show the infarct area with LV wall thinning (mean \pm SD) 


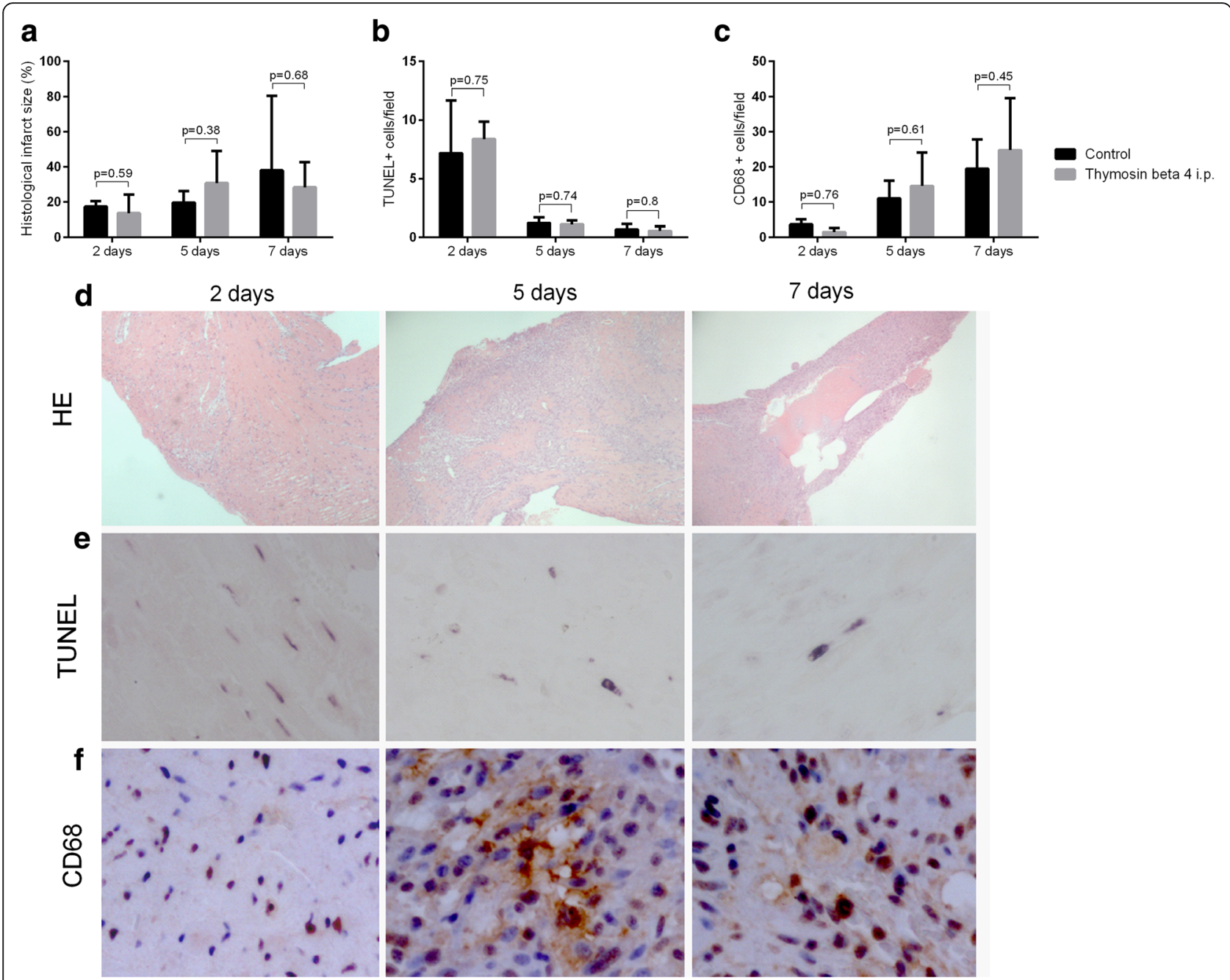

Fig. 2 Histological infarct size $\mathbf{a}$, TUNEL-positive cells $\mathbf{b}$ and CD68-positive cells $\mathbf{c}$ in controls and TB4 treated animals. Representative images of the infarct area on HE staining $\mathbf{d}$ TUNEL e and IHC for CD68 $\mathbf{f} 2,5$ and 7 days post MI (mean \pm SD)

\section{Discussion}

TB4 was cardioprotective after both intraperitoneal and intramyocardial delivery. Local administration seemed to be more effective although treatment was initiated 2 days later than after systemic administration. This is to our knowledge the first study comparing early and late functional and structural parameters and in this manner demonstrating favorable left ventricle remodeling in animals treated with TB4 after MI. The effect on left ventricle dilatation and reduction in EF was however smaller than in previously reported studies $[11,12]$. We determined infarct sizes by analyzing areas of the LV showing wall thinning and akinesia. During rest this can also be related to myocardial stunning. Stress echocardiography would have allowed for more sensitive differentiation between viable and non-viable myocardium but this is not feasible in rodents. We did however confirm myocardial scarring with histology. Mortality rates were similar between the groups with no survival benefit for the treated animals. The increased weight gain in controls compared to TB4 treated animals could be secondary to LV remodeling and developing heart failure.

On microarray analysis we identified significant upregulation of four genes after TB4 treatment. CD209f is a marker for antigen presenting dendritic cells which have a crucial role in regulating the inflammatory response after MI. After MI in humans the amount of myocardial CD209-positive cells correlates negatively with ventricular rupture and is associated with increased reparative fibrosis [13]. TB4 has in preclinical studies been shown to reduce the incidence of post-infarction LV rupture. Stard10 is involved in intracellular lipid transfer and has also been shown to be a signature epicardial gene that is down-regulated after MI in mice [10]. Several genes considered epicardial markers were here up-regulated in TB4 treated animals. This finding 
Table 3 Gene expression 2 days after myocardial infarction in controls and TB4 treated animals (top 20 genes)

\begin{tabular}{|c|c|c|c|c|}
\hline Gene name & Symbol & Probe_ID & Fold change $e^{a}$ & adj. $p$ val. \\
\hline START domain containing 10 & Stard10 & ILMN_2625601 & 2.6 & $<0.05$ \\
\hline Chitinase 3-like 1 & Chi3l1 & ILMN_2609813 & 2.0 & $<0.05$ \\
\hline Coiled-coil domain containing 80 & Ccdc80 & ILMN_1234824 & 2.0 & $<0.05$ \\
\hline CD209f antigen & $\mathrm{Cd} 209 \mathrm{f}$ & ILMN_2699665 & 1.7 & $<0.05$ \\
\hline Dermokine & Dmkn & ILMN_3105563 & 3.1 & 0.09 \\
\hline Solute carrier family 22 (organic cation transporter), member 1 & Slc22a1 & ILMN_1248318 & 3.3 & 0.10 \\
\hline $\begin{array}{l}\text { Nudix (nucleoside diphosphate linked moiety X)-type motif 4; } \\
\text { similar to Nudt4 protein }\end{array}$ & Nudt4 & ILMN_1252730 & 2.9 & 0.12 \\
\hline Alpha-2-HS-glycoprotein & Ahsg & ILMN_2764036 & 2.2 & 0.12 \\
\hline Uroplakin 3B & Upk3b & ILMN_2941714 & 3.4 & 0.17 \\
\hline Dickkopf homolog 3 (Xenopus laevis) & Dkk3 & ILMN_2852957 & 14.6 & 0.19 \\
\hline Protein phosphatase 1 , regulatory (inhibitor) subunit 1B & Ppp1r1b & ILMN_2954824 & 3.2 & 0.19 \\
\hline Synaptotagmin-like 2 & Syt12 & ILMN_3127335 & 2.3 & 0.19 \\
\hline Mucin 16 & Muc16 & ILMN_2631869 & 1.9 & 0.19 \\
\hline RAB33A, member of RAS oncogene family & Rab33a & ILMN_3161828 & 1.9 & 0.19 \\
\hline Ficolin A & Fena & ILMN_2718589 & 1.8 & 0.19 \\
\hline Retinoic acid receptor responder (tazarotene induced) 2 & Rarres2 & ILMN_3003130 & 1.8 & 0.19 \\
\hline WD repeat domain 92 & Wdr92 & ILMN_1225370 & 3.1 & 0.20 \\
\hline Complement component 2 (within $\mathrm{H}-2 \mathrm{~S}$ ) & C2 & ILMN_2612895 & 2.3 & 0.20 \\
\hline $\begin{array}{l}\text { Complement component 3; similar to complement component } \\
\text { C3 prepropeptide, last }\end{array}$ & C3 & ILMN_2759484 & 2.1 & 0.22 \\
\hline Double C2, gamma & Doc2g & ILMN_2704429 & 1.8 & 0.24 \\
\hline
\end{tabular}

mRNA expression analyzed by Illumina microarray (MouseWG-6 v2.0). $P$-values were adjusted by the Benjamini-Hochberg method

${ }^{\text {aTB4}}$ versus control

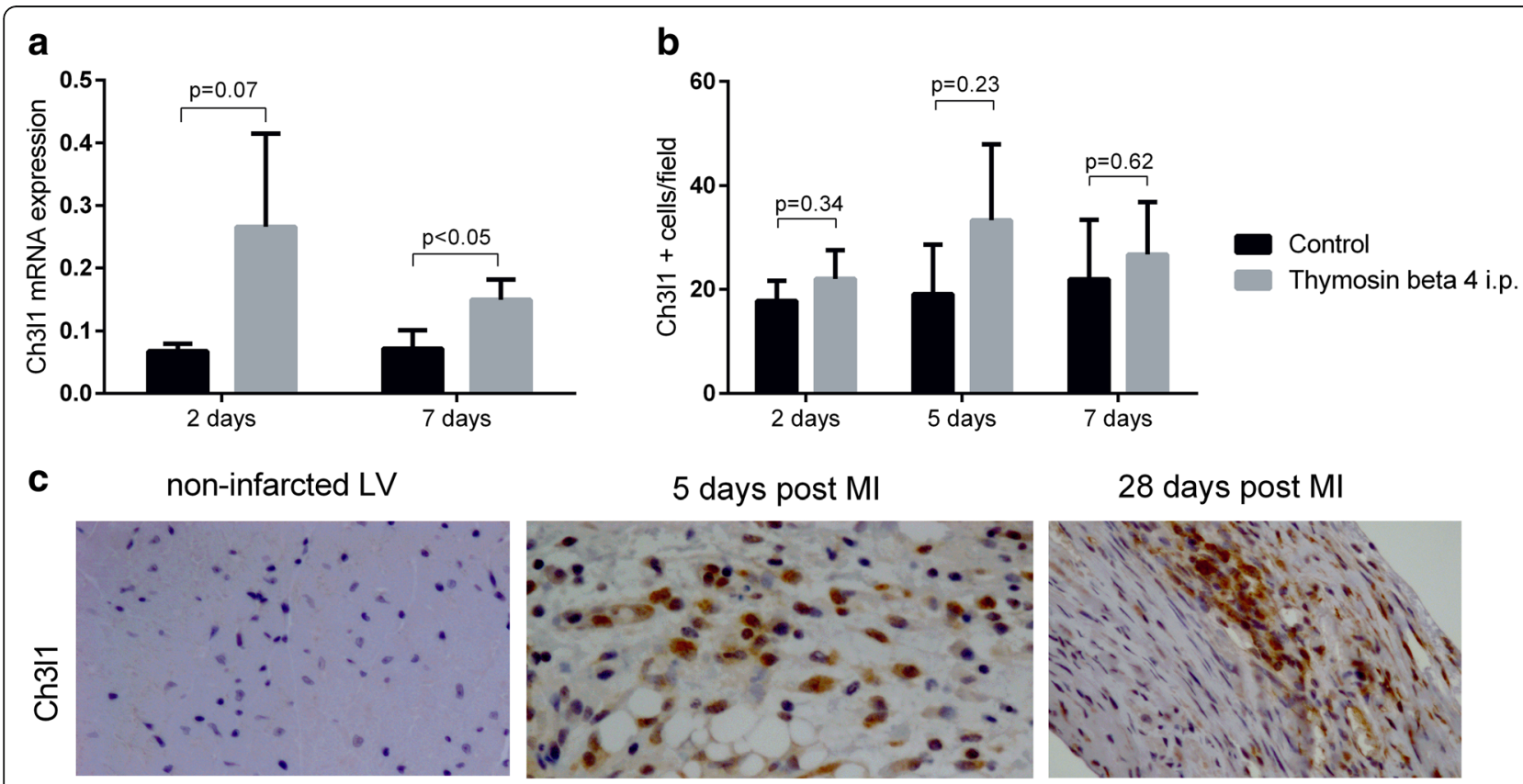

Fig. 3 Chitinase 3-like-1 mRNA expression a by qRT-PCR and Ch3l1 positive cells $\mathbf{b}$ in controls and TB4 treated animals. Representative IHC images for Ch3l1 in the non-infarcted myocardium and infarct area 5 days and 28 days post-Ml c (mean \pm SD) 


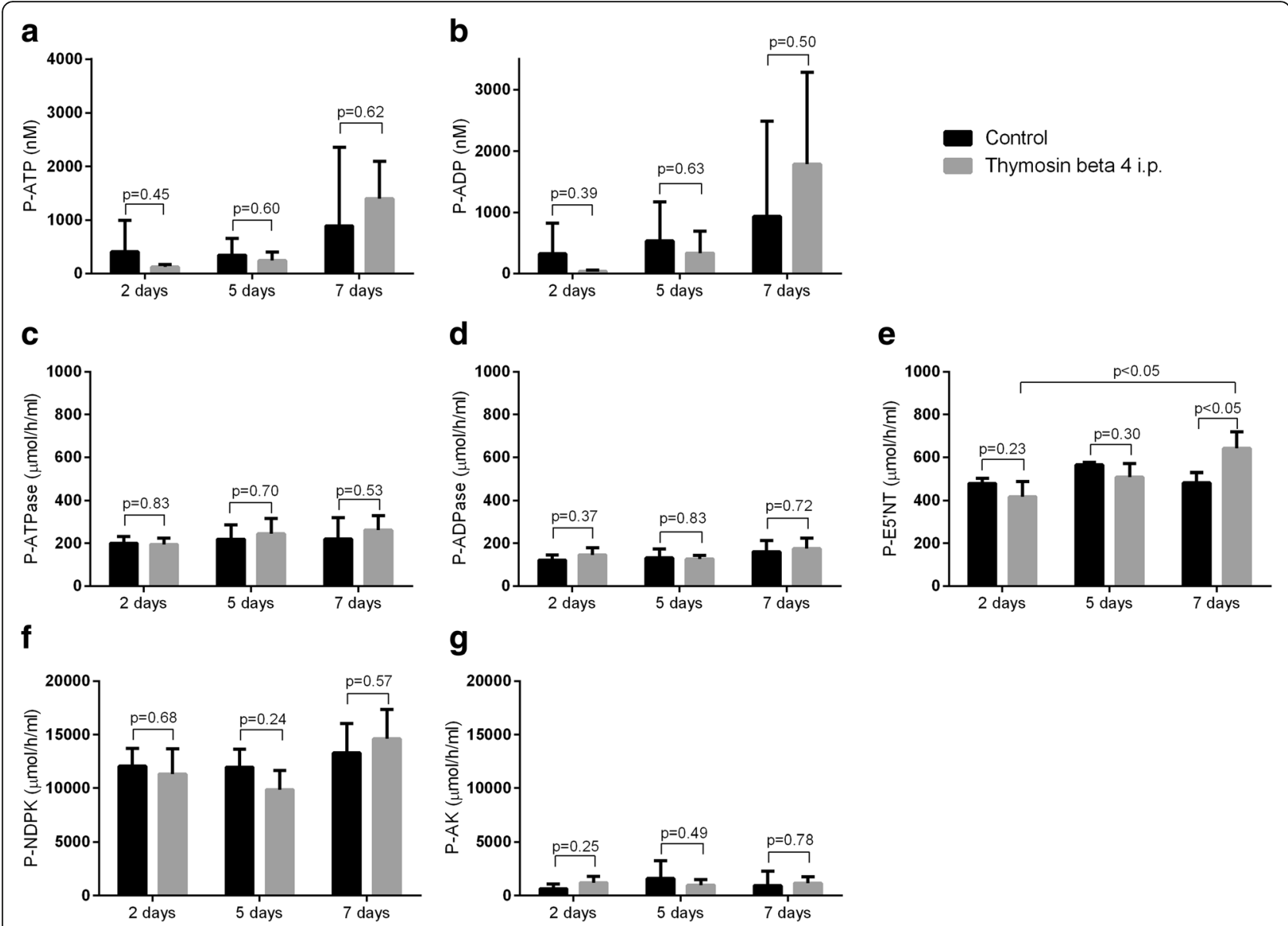

Fig. 4 Plasma ATP (a) and ADP (b) levels in controls and TB4 treated animals. Activity of hydrolyzing enzymes ATPase (c), ADPase (d) and 5'-ecto-nucleotidase or CD73 (e) in plasma of controls and TB4 treated animals. Enzymatic activity of kinases NDPK $\mathbf{f}$ and AK $\mathbf{g}$ in plasma of controls and TB4 treated animals (mean \pm SD)

could support earlier documentation on TB4 induced epicardial progenitor cell activation.

Ch311 or YKL-40 is a chitin binding protein secreted by macrophages, neutrophils and vascular smooth muscle cells and has recently gathered attention as a marker for inflammation and fibrosis [14]. We verified its up-regulation on microarray analysis by RT-PCR, where mRNA levels for Ch3l1 were higher in treated animals at days 2 and 7 post-MI compared to controls. Immunohistochemistry for Ch3l1 showed slightly more positive cells in the infarct area of TB4 treated animals at all time points. The positive cells located within the infarct area and could represent inflammatory cells, either macrophages or leukocytes. Positive staining for Ch3l1 was still observed 28 days after MI and the positive cells located in the fibrotic centre of the infarct area. Quantification of these cells was not performed because the positive cells were arranged densely without clearcut borders making it challenging to recognize individual cells on conventional ICH staining. In previous trials increased plasma levels of Ch3l1 has been found in patients during the first week after myocardial infarction and in some reports this elevation was still observed 1 month after the event. One study showed a negative correlation between maximal Ch3l1 levels and left ventricular EF recovery after MI. In patients receiving granulocyte-colony stimulating factor treatment there was an increase in plasma Ch3l1 but no correlation with cardiac recovery [15]. Patients suffering from MI often have several co-morbidities and are in a state of chronic inflammation. Direct comparison between MI patients and otherwise healthy laboratory animals is troublesome as the source of Ch3l1 is likely different. In our study peak mRNA expression for Ch311 was observed in TB4 treated animals 2 days after $\mathrm{MI}$ and remained higher at day 7 post-MI and the increase was also seen on histology. The different profile in Ch311 expression in the two groups could be related to TB4-mediated modification of the inflammatory response after MI. Ch3l1 binds to PAR2-receptors, which are expressed on cardiomyocytes but also on inflammatory cells. Ch3l1 treatment is associated with cardiomyocyte hypertrophy in vitro and has 
been shown to activate the survival kinase Akt pathway [16]. Pharmacological PAR2 activation offers cardioprotection after cardiac ischemia-reperfusion injury by reducing reactive oxygen species and inflammation [17]. TB4 in turn, increases Akt phosphorylation by acting through the focal adhesion complex [2]. The combined effects of TB4 and Ch3l1 could in theory enhance Akt-mediated signaling and further improve cardiomyocyte survival.

There were no differences in cardiomyocyte apoptosis or influx of CD68 positive macrophages during the first week after MI. The incidence of apoptotic cells decreased steadily between days 2 and 7. Measuring apoptosis at an earlier time point might have highlighted some differences between the groups. The amount of CD68 positive cells increased gradually from day 2 to day 7 after MI without differences between groups. In a previous study, it was reported that the peak influx of macrophages occurred 4 days after MI in TB4 treated mice and then decreased rapidly by day 7 [18]. The authors used a marker for M1 polarized macrophages as we also did in the present study. Therefore, the decrease in positive cells could also have been related to a switch in phenotype rather than a true decrease in macrophage number. We did not further investigate the phenotype of the cells in this study. This could have been valuable in order to identify proinflammatory (M1) and cardioprotective or reparative (M2) macrophages as Ch311 has previously been shown to play a role in M2 macrophage activation [19].

Recently it was reported that TB4 increases extracellular ATP synthesis and possibly induces purine receptormediated endothelial cell migration [3]. This encouraged us to screen plasma samples for ATP and ADP and for activities of soluble purine-converting enzymes. ATP is not able to diffuse across the cell membrane but is released after cellular damage or through several different transporters. In the heart ATP acts mainly on $\mathrm{P}_{2}$-receptors causing vasoconstriction and increased inotropy, but can also induce arrhythmias. ATP is a powerful chemoattractant for leukocytes and signaling through $\mathrm{P}_{2 \times 7}$-receptors induces inflammatory and apoptotic pathways [20]. In order to control ATP-mediated signaling, ATP is metabolized to ADP and further to AMP by different hydrolyzing enzymes, collectively called ATPases and ADPases. AMP in turn is hydrolyzed to adenosine by CD73. ADP is able to reduce ischemic damage in the heart by acting on $\mathrm{P}_{2 \mathrm{y}}$-receptors but is also a key transmitter in thrombosis formation. Adenosine in turn has showed several cardioprotective properties [18]. In this study plasma ATP and ADP levels were similar between the groups with a trend for higher overall levels at day 7 post MI. ATPase and ADPase activities were consistent during the first week. In TB4 treated animals the activity of CD73 continued to increase from day 2 to day 7 after infarction and at day 7 the activity was significantly higher than in controls. After myocardial damage, mainly inflammatory cell-derived CD73 is responsible for the local increase in Adenosine. This CD73-derived adenosine in turn reduces inflammation and can also enhance the activation of anti-inflammatory M2 macrophages, possibly suppressing the inflammatory reaction further [21]. Based on these findings, TB4's influence on purinergic signaling may not be limited to ATP synthase but might also involve other enzymes.

\section{Limitations}

In this study, we did not measure activities of known TB4-related pathways such as Akt phosphorylation nor did we directly measure adenosine concentrations. We did however demonstrate efficacy and displayed a therapeutic window for TB4 therapy 2 to 28 days after MI. In spite of small sample sizes in the short term study we were able to demonstrate significant changes in some of the parameters measured. These are however only observations and the underlying mechanisms will still have to be addressed in the future. We did not record infarct area but used infarct length as an endpoint in order to obtain comparable values between echocardiographic and histological measurements.

\section{Conclusions}

TB4 treatment reduced cardiac remodeling and improved function after MI. We can only speculate whether our findings on Ch3l1 up-regulation and increased CD73 activity are directly related to the therapeutic effects of TB4. There are however several common pathways for these molecules and this will provide interesting hypotheses for future studies.

\section{Abbreviations \\ ADP: Adenosine diphosphate; ADPase: Collective name for ADP hydrolyzing enzymes; AK: Adenylate kinase; Akt: Protein kinase B; ATP: Adenosine triphosphate; ATPase: Collective name for ATP hydrolyzing enzymes; ccdc80: coiled-coil domain containing 80; CD73: Ecto-5'-endonucleotidase; Ch311: Chitinase 3-like-1; EDV: End-diastolic volume; EF: Ejection fraction; ESV: End-systolic volume; LAD: Left anterior descending artery; LV: Left ventricle; MI: Myocardial infarction; mRNA: messenger ribonucleic acid; NDPK: Nucleoside diphosphate kinase; RT-PCR: Reverse transcriptase polymerase chain reaction; Stard10: Start domain containing 10; TB4: Thymosin beta 4; TUNEL: Terminal UDTP nick-end labeling}

\section{Acknowledgements}

We wish to thank laboratory technicians Sinikka Kollanus, Erika Nyman and Liisa Lempiäinen for excellent help with preparations of histological samples.

\section{Funding}

This work was supported by the clinical research funding (EVO) of Turku University Central Hospital. The funding body did not influence the study design, data analysis or writing of the manuscript.

Availability of data and materials

All data generated or analyzed during this study are included in this published article [and its supplementary information files]. 


\section{Authors' contributions}

The study was designed by CS, JK and TS. Animal experiments were performed by CS, RK and JK. Biochemical analyses were performed by CS, $\mathrm{MH}, \mathrm{PT}, \mathrm{AS}, \mathrm{T}-\mathrm{PA}$ and JK . The manuscript was written by CS and edited and accepted by all authors. All authors read and approved the final manuscript.

\section{Competing interests}

The authors declare that they have no competing interests.

\section{Consent for publication}

Not applicable.

\section{Ethics approval}

All animal experiments were approved by the regional state administrative agency of southern Finland.

\section{Author details}

${ }^{1}$ Research Centre of Applied and Preventive Cardiovascular Medicine, University of Turku, Turku, Finland. ${ }^{2}$ Children's Hospital, Pediatric Cardiology, Helsinki University Hospital, Helsinki, Finland. ${ }^{3}$ Department of Pathology, Turku University Hospital and University of Turku, Turku, Finland. ${ }^{4}$ Turku PET Centre, Turku University Hospital and University of Turku, Turku, Finland.

\section{Received: 23 November 2016 Accepted: 1 December 2016}

\section{Published online: 07 December 2016}

\section{References}

1. Bollini S, Riley P, Smart N. Thymosin $\beta 4$ : multiple functions inprotection repair andregenerationof the mammalian heart. Expert Opin Biol Ther. 2015;15(Suppl1):163-S174. doi:10.1517/14712598.2015.1022526.

2. Bock-Marquette I, Saxena A, White M, DiMaio M, Srivastava D. Thymosin $\beta 4$ activates integrin-linked kinase and promotes cardiac cell migration, survival and cardiac repair. Nature. 2004;432:466-72.

3. Freeman $\mathrm{K}$, Bowman $B$, Zetter B. Regenerative protein thymosin $\beta-4$ is a novel regulator of purinergic signaling. FASEB J. 2011;25:907-15. doi:10.1096/fj.10-169417.

4. Sopko N, Qin Y, Finan A, Dadabayev A, Chigurupati S, Qin J, et al. Significance of thymosin $\beta 4$ and implication of PINCH-1-ILK-a-Parvin (PIP) complex in human dilated cardiomyopathy. PLoS ONE. 2011;6(5):e20184. doi:10.1371/journal.pone.0020184.

5. Bao W, Ballard V, Needle S, Hoang B, Lenhard S, Tunstead J, et al. Cardioprotection by systemic dosing of thymosin beta four following ischemic myocardial injury. Front Pharm. 2013. doi:10.3389/fphar.2013.00149.

6. Stark C, Taimen P, Tarkia M, Pärkkä J, Saraste A, Alastalo T-P, et al. Therapeutic potential of thymosin $\beta 4$ in myocardial infarct and heart failure. Ann N Y Acad Sci. 2012;1269:117-24. doi:10.1111/j.1749-6632.2012.06695.x.

7. Koskenvuo J, Sievers R, Zhang Y, Angeli F, Lee B, Shih H, et al. Fractionation of mouse bone-marrow cells limits functional efficacy in non-reperfused mouse model of acute myocardial infarction. Ann Med. 2012;44(8):829-35. doi:10.3109/07853890.2012.672026.

8. Saraste A, Pulkki K, Kallajoki M, Henriksen K, Parvinen M, Voipio-Pulkki L. Apoptosis in human acute myocardial infarction. Circulation. 1997;95:320-3. doi:10.1161/01.CIR.95.2.320.

9. Helenius M, Vattulainen S, Orcholski M, Aho J, Komulainen A, Taimen P, et al. Suppression of endothelial CD39/ENTPD1 is associated with pulmonary vascular remodeling in pulmonary arterial hypertension. Am J Physiol Lung Cell Mol Physiol. 2015;308(10):L1046-57. doi:10.1152/ajplung. 00340.2014. Epub 2015 Mar 27.

10. Bochmann L, Sarathchandra P, Mori F, Lara-Pezzi E, Lazzaro D, Rosenthal N. Revealing New mouse epicardial cell markers throughTranscriptomics. PLoS ONE. 2010;5(6), e11429. doi:10.1371/journal.pone.0011429.

11. Hinkel R, Ball H, DiMaio M, Shrivastava S, Thatcher J, Singh A, et al. Cterminal variable AGES domain of Thymosin $\beta 4$ : the molecule's primary contribution in support of post-ischemic cardiac function and repair. J Mol Cel Card. 2015;87:113-25. doi:10.1016/j.yjmcc.2015.07.004.

12. Peng $H$, Xu J, Yang X, Dai X, Peterson E, Carretero O, et al. Thymosin- $\beta 4$ prevents cardiac rupture and improves cardiac function in mice with myocardial infarction. Am J Physiol Circ Physiol. 2014;307:H741-51. doi:10.1152/ajpheart.00129.2014.

13. Nagai T, Honda S, Sugano Y, Matsuyama T, Ohta-Ogo K, Asaumi Y, et al. Decreased myocardial dendritic cells is associated with impaired reparative fibrosis and development of cardiac rupture after myocardial infarction in humans. J Am Heart Assoc. 2014;3, e000839. doi:10.1161/JAHA.114.000839.

14. Kastrup J. Can YKL-40 be a new inflammatory biomarker in cardiovascular disease? Immunobiology. 2012;217:483-91. doi:10.1016/j.imbio.2011.04.007.

15. Hedegard A, Ripa R, Johansen J, Jorgensen E, Kastrup J. Plasma YKL-40 and recovery of left ventricular function after acute myocardial infarction. Scand J Clin Lab Inv. 2010;70(2):80-6. doi:10.3109/00365510903518191.

16. Görgens S, Hjorth M, Eckardt K, Wichert S, Norheim F, Holen T, et al. The exercise-regulated myokine chitinase-3-like protein 1 stimulates human myocyte proliferation. Acta Physiol. 2016;216:330-45. doi:10.1111/apha.12579.

17. Antoniak S, Pawlinski R, Mackman N. Protease-activated receptors and myocardial infarction. IUBMB Life. 2011;63(6):383-9. doi:10.1002/iub.441.

18. Evans M, Smart N, Dubé K, Bollini S, Clark J, Evans H, et al. Thymosin $\beta 4$ sulfoxide attenuates inflammatory cell infiltration and promotes cardiac wound healing. Nat Commun. 2013;4:2081. doi:10.1038/ncomms3081.

19. Mack I, Hector A, Ballbach M, Kohlhäufl J, Fuchs K, Weber A, et al. The role of chitin, chitinases, and chitinase-like proteins in pediatric lung diseases Mack et al. Mol Cell Pediatr. 2015;2:3. doi:10.1186/s40348-015-0014-6.

20. Zhao H, Kilgas S, Alam A, Eguchi S, Ma D. The role of extracellular adenosine tripohosphate in ischemic organ injury. Crit Care Med. 2016. doi:10.1097/CCM.0000000000001603.

21. Bönner F, Borg N, Jacoby C, Temme S, Ding Z, Flögel U, et al. Ecto-5'nucleotidase on immune cells protects from adverse cardiac remodeling. Circ Res. 2013;113:301.312. doi:10.1161/CIRCRESAHA.113.300180.

\section{Submit your next manuscript to BioMed Central and we will help you at every step:}

- We accept pre-submission inquiries

- Our selector tool helps you to find the most relevant journal

- We provide round the clock customer support

- Convenient online submission

- Thorough peer review

- Inclusion in PubMed and all major indexing services

- Maximum visibility for your research

Submit your manuscript at www.biomedcentral.com/submit
) Biomed Central 